Title: The feasibility of psychometric measures for body image and lymphedema for routine practice 


\begin{abstract}
Research Question: To assess the feasibility of the MGSIS-5and G3L-20 in a community sample of cisgender men aged 40 years and older

Research problem: Psychometric measures can aid urologic practice by prompting patients to talk about aspects of their body that are either too sensitive or a natural part of aging. Importantly, reliable and valid measures can also contribute to a an evidenced-based-practice-based-evidence cycle where they can establish the impact of changes recommended by research while using the results in turn to inform research. In this study, we examine two psychometric measures on the opposite ends of a psychological-physical continuum; the Male Genital Self-Image Scale (MGSIS5) and the Groin and Lower Limb Lymphedema questionnaire (G3L-20)
\end{abstract}

Methodology: Non-experimental psychometric design administering the questionnaires online to a community sample of cisgender men aged 40 years old and above. Validity and reliability analyses were conducted.

Results: 30 men completed the study; 14 aged 40-49, 14 aged 50-59 and 2 aged 60-69. The MGSIS-5 and G3L-20 show acceptable reliability and validity with one- and three-component structures respectively.

Conclusions: The MGSIS-5 and G3L-20 show sufficient feasibility to justify the resources for studies with larger community samples and for pilot studies with clinical populations.

Keywords: quality of life; genital body image; psychometric measures; lymphedema 


\section{The feasibility of psychometric measures for body image and lymphedema for}

\section{routine practice}

Psychometric measures can aid urologic nursing. There are reports of a reluctance of men to disclose treatment effects to others, due to embarrassment, fear of appearing weak, and/or the loss of masculine capital ${ }^{1}$ or because the impact on their body of their condition is too traumatising ${ }^{2}$. Mroz et al. ${ }^{3}$ found that although men did on occasion open up about their experiences; they often spoke in general terms rather than discussing detail, particularly about the emotional consequences of their physical symptoms. Men are likely to couch their discussions about sensitive topics in humour, perhaps in an attempt to safely reveal emotional states without revealing too much vulnerability ${ }^{4-6}$. This can make communication challenging for health professionals, especially as sexual and urinary functioning can be considered intimate and off-limits for discussion with strangers ${ }^{7}$. The prevalence of many urological conditions increases with age, and Balderson and Towell ${ }^{8}$ suggest that older men in particular are likely to suffer in silence. Also, changes in sexual and urinary function are often considered to be natural and expected with age ${ }^{9}$ and therefore go unmentioned. Consequently, psychometric measures may prove useful; particularly because some men are more likely to monitor their health by numbers than subjective feelings ${ }^{10}$ and that a questionnaires gives tacit approval required to free patients up to discuss an issue ${ }^{11}$, which is evidenced with more in-depth discussion on the questionnaire topic with a clinician ${ }^{12}$.

Furthermore, the routine use of psychometric measures in urological nursing offers a virtuous evidenced-based-practice-based-evidence circle ${ }^{13}$. The use of carefully selected psychometric measures can, for example, help establish the impact of changes in practice recommended by research. In turn, the results from reliable 
and valid measures from routine practice can inform research. This is particularly important for rare conditions in urological nursing that struggle to gain the resources for developments in either practice or research. Where psychometric measures are routinely collected, these could be - with patient consent - used to complement practice and research developments, minimizing costs. The International Penile Advanced Trial (InPACT; ISRCTN13580965), is an example that aims to determine i) if there is a role for neoadjuvant therapy in this patient group and ii) if prophylactic pelvic lymph node dissection improves survival in patients at high risk of recurrence following inguinal lymph node dissection. InPACT has included a psychometric measure to examine quality of life but this adds to the financial burden of a study that is already complicated by governance across international borders and time (requiring ten years to recruit sufficient participants). This paper two considers two potential areas for urological practice that are at the opposite end of a continuum of psychological-physical; genital body image and lymphedema.

\section{Body Image}

A body image is a representation (the 'image') that an individual has about their material form. Schilder ${ }^{14}$ introduced the notion of body image in reference to physiology and phenomenology. There are, for example, "tactile, thermal, pain impressions" from the "muscles" as well as "the immediate experience that there is a unity of the body" 14(p11). In relation to body image, some parts of the body are particularly important sources of information as 1) a site of breach between the body and outer world and 2) a location of inner, bodily sensation. As Schilder explains, the mouth, urethra and anus are openings into and out of the body and through which "we come in closest contact with the world" 14(p124). Like irritated skin compelling an itch, the genitals, for example, forces "the individual into a continual contact with the 
outside world, and there is no question that we discover our bod at least partially by these contacts with the outside world" 14(p125). A genital body image measure could examine satisfaction with the i) appearance, size and feelings towards the genitals in general as well as the ii) appearance, amount, colour, shape, size, smell, and texture of the parts.

Measuring genital body image could be useful across a range of urological practice. Asking patients to complete a questionnaire before an appointment could, for example, give them tacit approval ${ }^{11}$ to talk about issues that they find sensitive because it is challenging to their sense masculinity $2,5,15-18$, easing communication between patient and health professionals. The European Organisation for Research and Treatment of Cancer Quality of Life measure EORTC-QLQ; 19, Clinical Outcomes in Routine Evaluation CORE; 20 and the International Index of Erectile Function IIEF; 21 are examples of psychometric measures used that are both well validated and general enough that they can be used across a range of settings. The EORTC-QLQ and the CORE-6D are specific to caner care and psychological services respectively, although one could argue that the questions are general enough that they could be used in any clinical setting. Nevertheless, the questions may be so generic that they are not useful for urologic practice. It is unlikely, for example, that the questions would prompt patients to talk about their genitals. In contrast, the IIEF is relevant for urological practice, but its focus on erectile function means it is arguably insensitive for those patients who have lost function, such as due to penectomy. Instead, genital body image could offer the right balance in being relevant for urological conditions while still being general enough that it avoided a proliferation of measures. There Male Genital Self-Image Scale is a short measure that could be useful although it has to date only be developed in young men MGSIS-5; 22 . 


\section{Lymphedema}

Lymphedema is a useful counterpoint to genital body image because it is focused on a specific set of physical symptoms rather than a psychological construction. Indeed, there are a wide range of questionnaires examining physical symptoms, such as pain; these are treated as if they are diagnostic tools although there are technically psychometric measures attempting to quantify a person's subjective experience of their body. A consequently, a psychometric measure of genital and lower limb lymphedema offers much of the same potential benefits of a genital body image measure; it may prompt patients to talk about pain and swelling in their groin and lower limbs and, if a clinical threshold is met, could direct health professionals to, for example, follow up with a physical examination.

The Gynaecologic Cancer Lymphedema Questionnaire was developed as a diagnostic tool for women who had received a diagnosis of and treatment for specific gynaecological cancers to identify lymphedema in the lower extremities GCLQ-20; 23 . Only a single item is sex-specific, so this could easily be adapted for men as the Groin and Lower Limb Lymphedema scale (G3L-20). Noble-Jones ${ }^{24}$ recent research on the Lymphoedema Genitourinary Cancer Questionnaire does something similar with male patients but was published after the research in this manuscript commenced thus demonstrating the importance of this topic at this time.

\section{Aims}

To be able to examine the reliability and validity of genital body image and lymphedema psychometric measures with urology patients, it is important to examine their use in community populations first. Furthermore, psychometric tests must reflect the demographics of those most commonly identify with the conditions they measure. Consequently, the aim of this study is to assess the feasibility of the 
MGSIS-5and G3L-20 in a community sample of cisgender men aged 40 years and older.

\section{Method}

This study used a non-experimental psychometric design to administer the questionnaires and assess their psychometric properties.

\section{Participants}

The aim of the sampling strategy was to recruit cis-gender male participants who reflected the age of the population of interest and who self-identified as healthy and residing in the United Kingdom. From those completing the questionnaires, 30 were suitable for inclusion. To ensure data collection was in proportion to the aims of a feasibility study, the only demographic information collect was self-reported age category at the time of completion; 14 were aged 40-49, 14 were 50-59, and 2 were 60-69.

\section{Materials}

The study used two questionnaires. The first was the five-item male genital self-image scale MGSIs-5; 22. The items were; I feel positive about my genitals, I am satisfied with my genitals, I would feel comfortable letting a sexual partner look at my genitals, I think my genitals work the way they are supposed to work; and I am not embarrassed about my genitals. Responses on the MGSIS-5 were given using a 4option Likert with 'agreement' showing positive genital self-image; Strongly agree $=$ 4, agree $=3$, disagree $=2$, strongly disagree $=1$.

The second questionnaire was an adapted version of the Gynecologic Cancer Lymphedema Questionnaire GCLQ; 23. The GCLQ was originally developed for gynecologic cancer survivors and had 20 items that were answered yes/no. The 
questionnaire asked if the respondent had experienced limited movement, weakness, tenderness, swelling, redness, blistering, firmness, increased temperature, heaviness, numbness, stiffness, aching or pockets of fluid in the groin and lower limbs in the last four weeks. All but one questions were suitable regardless of sex identity, except for number 19 which clarified that 'grown swelling' related to the 'labia/vulvar'. In the adapted version used in this study - termed the Groin and Lower Limb Lymphedema scale (G3L-20) - labia/vulvar was removed (See Table 1). The yes/no answers are scored as 1 and 0 respectively, which means a higher score (from 0 to 20) shows greater experience in the range of symptoms associated with lower limb lymphedema. Carter et al. (ibid.) showed the plausible clinical cut-off scores are in the range of 3 to 6.

INSERT TABLE 1 AROUND HERE

\section{Statistical Analysis}

Validity was examined using an exploratory factor analysis to identify psychometric factors, which was followed by a confirmatory factor analysis. Internal reliability of the items in each measure was assessed using Chronbach's alpha. To minimize risk of bias in the statistical analysis, the proposal was registered before data collection and the data was archived to allow others to check and reuse ${ }^{25}$.

\section{Procedure}

The study was administered online. Invitations to participate were shared on social media and websites who had men aged 40 years and older as their audience, such as the NHS Men's Health forum (https://healthunlocked.com/menshealth). Actively clicking a link in the invitation took participants to a page explaining the study. Again, participants had to actively click a link to find the questionnaire. The study started by confirming UK residence, age and that they were free from illness. 
Those that met the inclusion criteria were taken on to complete the MGSI and the G3L-20; 15 respondents attempted the study but because they did not meet the inclusion criteria were branched to the end. Only at the end when respondents confirmed their responses was data stored. The questionnaire was hosted on Microsoft Forms, which met standard C of the Office 365 Compliance Framework for security and privacy 26 .

\section{Research Governance}

Ethical review was provided under the University of Bradford Research with Human Participants policy. Limited demographic - for example, age range rather than age - information was collected to minimize intrusion. Consent was explicit at the start of the questionnaire (those not consenting where branched to the end of the online form) and included public archiving of the study data to confirm the analysis in this paper and to facilitate secondary analyses.

\section{Findings}

\section{Male Genital Self-Image Scale (MGSIS-5)}

The first questionnaire is the Male Genital Self-Image Scale. The means for the individual questions and total score of the MGSIS-5 indicate a positive genital self-image in the tested participants with $70 \%$ either agreeing or strongly agreeing with all positive items (See Table 2). Only two (6.7\%) participants reported that they did not feel positively about their genitals, and only one (3.3\%) reported that he would not feel comfortable letting a sexual partner look at their genitals. In total, four participants (13.3\%) each suggested a dissatisfaction with appearance, a belief that their genitals did not work as they were supposed to, and embarrassment towards their genitals. There were very few differences in scores between age groups. The most 
notable difference is in the question about genital function which elicited a slightly lower score in those aged 50-59 compared with the 40-49 year-old group.

\section{INSERT TABLE 2 AROUND HERE}

A principal component analysis (PCA) was performed to assess the psychometric components of the MGSIS-5. The correlation matrix indicated that all variables had at least one correlation coefficient over 0.3. Further, the Kaiser-MeyerOlkin measure (KMO) had a value of 0.80 , suggested by Kaiser ${ }^{27}$ to be 'meritorious' and indicating an adequate sample. Finally, Bartlett's test of Sphericity was statistically significant $(\mathrm{p}<.0005)$. All of these results suggested that PCA was an appropriate analysis to perform on the data.

Only one component with an eigenvalue above one emerged from the PCA and explained $68.45 \%$ of the variance (See Table 3). A second component with an eigenvalue of 0.79 would explain a further $15.70 \%$ of the variance, however, from scrutinizing the scree plot and the component matrix it was decided that this was not significant. From the available data, the MGSIS-5 appears to be measuring only one meaningful component.

\section{INSERT TABLE 3 AROUND HERE}

Cronbach's Alpha was used to ascertain the internal consistency reliability. The data produced a score of 0.88 indicating a high level of internal consistency. Similarly, no item deletion would result in a higher Cronbach's Alpha, suggesting that each individual question is appropriate to the scale.

\section{Groin and Lower Limb Lymphedema Scale (G3L-20)}

The mean total score for the G3L-20 was 1.20 with a standard deviation of 3.54 (see Table 4). As Carter ${ }^{23}$ showed that plausible clinical cut-off scores are in the range of 3 to 6 , there is some risk of erroneously detecting lymphedema. In this 
study, a clinical cut-off of 6 would mean that all participants would have been correctly identified as free from lymphedema.

Insert Table 4 Around Here

There were only 2 participants aged 60-69 and they responded negatively to every question on the GCLQ, so their individual scores have not been reported here. There were some differences in scores between the 40-49 and the 50-59 age group. Those aged 50-59 had a slightly higher overall score, and a far higher response in the affirmative to the question about aching. Nearly two thirds $(64.3 \%)$ of 50-59-year-old participants said that they had experienced aching in their lower body, as compared to $14.3 \%$ in the $40-49$ age group. There were no participants who answered in the affirmative to questions regarding hip swelling and groin swelling, so these were removed from further analysis as there was no variation to measure.

It was not possible to produce the KMO measure of Bartlett's test of Sphericity. Although all variables did have a correlation coefficient about 0.3 , the other assumptions necessary to perform PCA could not be tested, which means the results should be approached with caution.

A total of five components with an eigenvalue greater than one emerged in the analysis, which explained $85.72 \%$ of the variance in total $(45.91 \%, 17.33 \%, 9.91 \%$, $6.69 \%$ and $5.89 \%$ respectively; see Table 5). However, the scree plot suggested that only three of these components should be retained, hence it was decided that a threecomponent model which explained $73.15 \%$ of the variance was the best fit and had the benefit of a simpler structure. There was some overlap between components, but component one strongly loaded to items regarding the feeling and function of the underlying structure of the legs, while component two loaded to items regarding the exterior feeling and function of the skin. Component three mainly loaded to items 
related to the skin's appearance, although it did also load to the question regarding limited movement of the hip.

Insert Table 5 Around Here

As with the MGSIS-5 data, Cronbach's Alpha was used to ascertain the internal consistency reliability coefficient. The score of 0.92 suggests that the adapted GCLQ has a very high level of internal consistency. The data does suggest that the removal of questions regarding limited movement of the hip, limited movement of the toes, or increased temperature of the leg would result in a higher score, however the increase would not be great enough to definitively recommend the removal of these items.

\section{Conclusions}

The aim of this paper was to examine the feasibility of the MGSI-5 and the G3L-20 for use in UK clinical urology groups aged. This was achieved through a psychometric study of the two measures in a community sample of men aged 40 years and above. The data analysis shows that we can conclude that the resources would be justified for larger community samples and it would be appropriate to assess their feasibility in clinical populations.

\section{MGSI}

The MGSI was first developed in young male community sample, so this study shows good feasibility in for men in the UK. At present, there is no information from which plausible clinical cutoffs could be developed, so studies comparing community and clinical groups would be useful. Even without clinical cutoffs, completing the MGSI before meeting a health professional may prime patients to discuss their genitals. This means that future studies into the utility of the MGSI in 
urology groups should not limit themselves to psychometric designs so that they are open to examining how their use impacts on clinical encounters.

The results tend to lend support to the validity of both the MGSIS-5 and the adapted version of the GCLQ in UK based men aged 40 and over. The means for the individual item scores were very similar to those obtained in the original paper on the development and validation of the MGSIS-5 by Herbenick et al. ${ }^{22}$, who also arrived at a one component solution.

The question with the highest mean score (3.43) was related to comfort with letting a sexual partner look at the participants' genitals, while the lowest mean (3.10) was about satisfaction with appearance. Initially, this may appear counterintuitive as it would make sense for comfort felt when someone else can see a man's genitals to be related to his perception of their appearance. However, it may be that the men questioned associated a partner looking at their genitals with some pleasurable sexual activity and thus would be less concerned with issues surrounding genital appearance. It is not known whether there would be a difference in ratings were the question simply asking about the prospect of anyone else looking at the participants' genitals rather than specifically a sexual partner, though it seems reasonable to assume that in that instance the score would be more closely related to the man's perception of his genital appearance. Nevertheless, the focus on the sexual aspect may have more utility, as it could suggest whether poor genital self-image is interfering with a man's engagement with and enjoyment of healthy sexual activity.

\section{GCLQ}

The mean total score of the participants measured here (1.97) matched closely with that of the group without a diagnosis of lymphedema (1.63) in the original study in women (Carter et al. 2010) ${ }^{23}$. This suggests that the adapted version of the GCLQ 
was not detecting lymphedema in participants in error and that it would be an appropriate measure to use in men of this demographic. Similarly, the internal reliability coefficient (Cronbach's Alpha) was high (0.92) and tallied well with the original research (0.95), confirming a good level of internal reliability for the measure. The analysis did show indicate a three-factor structure but the crossovers between some questions this should be taken cautiously. Nevertheless, these findings justify the resources for a replication with a larger community sample, which would most likely result in a more discrete component structure.

It is difficult to directly compare the results obtained here with those from the original development paper by Carter et al. ${ }^{23}$ as they were measuring very different demographics. While the original was comparing women both with and without a diagnosis of lymphedema who had experienced cancer treatment, the present study was measuring healthy men. Perhaps due to this, some of the responses for individual items differed quite significantly, but the similarity in the means of the total scores demonstrate a promising synchronicity that suggests the validity of the measure in a male cohort.

The most striking age difference appears in the question related to aching. Only $14.3 \%$ of participants in the $40-49$ age group answered in the affirmative to this question, as compared with $64.3 \%$ of those aged $50-59$. Molton and Terrill ${ }^{28}$ suggest that incidences of chronic pain begin to increase after 45 , which may be an explanation for this result. However, the difference in reported lower body aches found here appears to be particularly large. Though there were only two participants aged 60-69, neither of those reported aching. Should the increase in aching be so significant after 45 , it would be expected that it would continue beyond that point, 
which from these results does not appear to be the case. It would be interesting to see if this effect is still evident in a larger community sample.

The questions with the next highest affirmative response were related to numbness and limited movement of the knee, both of which were reported by $16.7 \%$ of the participants. Relph and Herrington ${ }^{29}$ report that a reduction in knee mobility is common as a person ages, which could explain why this was one of the most commonly reported issues. Issues surrounding numbness is more difficult to explain, as numbness is generally not a common sign of ageing but usually a symptom of some neuropathic illness or injury ${ }^{30}$. As participants were asked to confirm that they did not have a specific illness which could affect the function of their lower limbs, the question may be poorly worded and causing confusion. It is possible that some participants classified a common phenomenon such as pins and needles as numbness. This may be something which requires further clarification in the future use of the G3L-20.

\section{Limitations}

Feasibility studies are an important step in the development of psychometric measures. Nevertheless, the nature of statistics employed in this study means that robustness of the findings increases along with the sample size ${ }^{31}$, which means are futures studies with larger samples are important. Temporal reliability was not explored here but is nevertheless important, particularly for a measure that could have clinical applications. Future studies should include examining test-re-tests reliability.

The online based recruitment method may have affected the representativeness of the sample ${ }^{32}$, particularly among the target demographic. Weigold et al. ${ }^{33}$ suggest that results obtained from older adults results could be quantitatively and qualitatively different than if they had completed the measures using same pen and paper. They 
posit that relative unfamiliarity with the technology could contribute to increased strain on the participants' processing capacity, resulting in inaccurate results. This could explain the imbalance in participation as age increased. 28 of the 30 participants whose data could be used were aged between 40 and 59, while only two were 60-69. There was only one person aged 70 or over who participated, but unfortunately his data could not be used as he had a pre-existing condition. However, as the present study was self-selecting, it seems likely that participants already had a certain level of familiarity with the technology

In older adults, self-selecting samples on Internet-based studies can have unique characteristics ${ }^{34-37}$, such as have increased psychological wellbeing ${ }^{38}$. As a community population study, this is a potentially beneficial bias although it does reinforce the importance of developing these measures with clinical populations. However, when developing clinical cut-offs, it is important to avoid over-inflating or deflating baseline scores. Future community and clinical studies will have to avoid an overreliance on Internet-based recruitment.

Box 1: What this manuscript contributes

- The Male Genital Self-Image Scale (MGSIS-5) has been developed in a young American population and could be useful in routine urological practice, such as for prompting patients to talk about sensitive issues during an initial assessment

- The Gynecologic Cancer Lymphedema Questionnaire could be adapted for use with men, directing health professions to consider lymphedema when clinical cut-offs are reached 
- Both the MGSIS-5 and the Groin and Lower Limb Lymphedema scale (G3L-

20) show good feasibility, which justifies the resources for larger community samples and feasibility trails in clinical populations

\section{References}

1. Grunfeld EA, Drudge-Coates L, Rixon L, Eaton E, Cooper AF. "The only way I know how to live is to work": A qualitative study of work following treatment for prostate cancer. Health Psychology. 2013;32(1):75-82. doi: $10.1037 / \mathrm{a} 0030387$

2. Branney P, Witty K. Hidden, Visceral and Traumatic: A Dramaturgical Approach to Men Talking about Their Penis after Surgery for Penile Cancer. PsyArXiv; 2018. doi:10.31234/osf.io/dxnp6

3. Mróz LW, Oliffe JL, Davison BJ. Masculinities and patient perspectives of communication about active surveillance for prostate cancer. Health Psychology. 2013;32(1):83-90. doi:10.1037/a0029934

4. Branney P, Witty K, Braybrook D, Bullen K, White A, Eardley I. Masculinities, humour and care for penile cancer: a qualitative study. Journal of Advanced Nursing. 2014;70(9):2051-2060. doi:10.1111/JAN.12363

5. Branney P, Witty K. Ostensibly inappropriate humour: A case study of an emotional rupture. In: Phillips H, ed. Humor: Emotional Aspects, Role in Social Interactions and Health Effects. NY: Nova; 2016:115-136.

https://www.novapublishers.com/catalog/product_info.php?products_id=57694.

6. Seymour-Smith S. A reconsideration of the gendered mechanisms of support in online interactions about testicular implants: A discursive approach. Health Psychology. 2013;32(1):91-99. doi:10/f496hr

7. Skea ZC, MacLennan SJ, Entwistle VA, N'Dow J. Communicating good care: A qualitative study of what people with urological cancer value in interactions with health care providers. European Journal of Oncology Nursing. 2014;18(1):3540. doi:10.1016/j.ejon.2013.09.009

8. Balderson N, Towell T. The prevalence and predictors of psychological distress in men with prostate cancer who are seeking support. British Journal of Health Psychology. 2003;8(2):125-134. doi:10.1348/135910703321649114

9. Dubeau CE. The aging lower urinary tract. J Urol. 2006;175(3 Pt 2):S11-15. doi:10.1016/S0022-5347(05)00311-3

10. Calasanti T, Pietilä I, Ojala H, King N. Men, bodily control, and health behaviors: The importance of age. Health Psychology. 2013;32(1):15-23. doi:10.1037/A0029300 
11. Powel LL, Clark JA. The value of the marginalia as an adjunct to structured questionnaires: Experiences of men after prostate cancer surgery. Quality of Life Research. 2005;14(3):827-835. doi:10/c7wjmb

12. Hartmann U, Burkart M. Erectile Dysfunctions in Patient-Physician Communication: Optimized Strategies for Addressing Sexual Issues and the Benefit of Using a Patient Questionnaire. The Journal of Sexual Medicine. 2007;4(1):38-46. doi:10.1111/j.1743-6109.2006.00385.x

13. Branney P, Barkham M. Core outcomes in psychosexual therapy: A feasibility study of the CORE-OM. Sexual and Relationship Therapy. 2006;21(1):15-26. doi:10.1080/14681990500281414

14. Schilder P. The Image and Appearance of the Human Body: Studies in the Constructive Energies of the Psyche. Repr. London: Routledge; 2000.

15. Bullen K, Edwards S, Marke V, Matthews S. Looking past the obvious: experiences of altered masculinity in penile cancer. Psycho-Oncology. 2010;19(9):933-940. doi:10.1002/PON.1642

16. Bullen K, Matthews S, Edwards S, Marke V. Exploring men's experiences of penile cancer to improve rehabilitation. Nursing Times. 2009;105(12):20-24.

17. Bullen K, Tod D. Men and masculinity: understanding the challenges for urological cancer. Trends in Urology. 2013;4(4):9-12. doi:10.1002/TRE.338

18. Witty K, Branney P, Evans J, Bullen K, White A, Eardley I. The impact of surgical treatment for penile cancer - Patients' perspectives. European Journal of Oncology Nursing. 2013;17(5):661-667. doi:10.1016/J.EJON.2013.06.004

19. Fayers P, Bottomley A. Quality of life research within the EORTC - the EORTC QLQ-C30. European Journal of Cancer. 2002;38, Supplement 4(0):125-133. doi: $10 / \mathrm{b} 2 \mathrm{dk} 2 \mathrm{~s}$

20. Mavranezouli I, Brazier JE, Young TA, Barkham M. Using Rasch analysis to form plausible health states amenable to valuation: the development of CORE6D from a measure of common mental health problems (CORE-OM). Quality of Life Research. 2011;20(3):321-333. doi:10/c74km7

21. Rosen RC, Riley A, Wagner G, Osterloh IH, Kirkpatrick J, Mishra A. The international index of erectile function (IIEF): a multidimensional scale for assessment of erectile dysfunction. Urology. 1997;49(6):822-830. doi:10/cr94np

22. Herbenick D, Schick V, Reece M, Sanders SA, Fortenberry JD. The Development and Validation of the Male Genital Self-Image Scale: Results from a Nationally Representative Probability Sample of Men in the United States. The Journal of Sexual Medicine. 2013;10(6):1516-1525. doi:10/f47sq8

23. Carter J, Raviv L, Appollo K, Baser RE, Iasonos A, Barakat RR. A pilot study using the Gynecologic Cancer Lymphedema Questionnaire (GCLQ) as a clinical care tool to identify lower extremity lymphedema in gynecologic cancer 
survivors. Gynecologic Oncology. 2010;117(2):317-323.

doi:10.1016/J.YGYNO.2010.01.022

24. Noble-Jones R, Thomas MJ, Bose P. The Lymphoedema Genitourinary Cancer Questionnaire in urology follow-up clinics. International Journal of Urological Nursing. 2019;13(1):5-12. doi:10/gfxj76

25. Hollyhead C, Branney P. Assessing the validity of the Male Genital Self-Image Scale and the Gynaecologic Cancer Lymphedema Questionnaire in a UK population of healthy males over forty. August 2018. doi:10.17605/osf.io/5vhju

26. Security and Privacy in Microsoft Forms. https://support.office.com/enie/article/security-and-privacy-in-microsoft-forms-7e57f9ba-4aeb-4b1b-9e21b75318532cd9. Accessed July 17, 2019.

27. Kaiser HF. An index of factorial simplicity. Psychometrika. 1974;39(1):31-36. doi:10.1007/BF02291575

28. Molton IR, Terrill AL. Overview of persistent pain in older adults. American Psychologist. 2014;69(2):197-207. doi:10.1037/a0035794

29. Relph N, Herrington L. The effects of knee direction, physical activity and age on knee joint position sense. The Knee. 2016;23(3):393-398.

doi:10.1016/j.knee.2016.02.018

30. Lange-Maia BS, Newman AB, Cauley JA, et al. Sensorimotor Peripheral Nerve Function and the Longitudinal Relationship With Endurance Walking in the Health, Aging and Body Composition Study. Archives of Physical Medicine and Rehabilitation. 2016;97(1):45-52. doi:10.1016/j.apmr.2015.08.423

31. Brown TA. Confirmatory Factor Analysis for Applied Research. Second edition. New York; London: The Guilford Press; 2015.

32. Khazaal Y, van Singer M, Chatton A, et al. Does Self-Selection Affect Samples' Representativeness in Online Surveys? An Investigation in Online Video Game Research. Journal of Medical Internet Research. 2014;16(7):e164. doi:10.2196/jmir.2759

33. Weigold A, Weigold IK, Drakeford NM, Dykema SA, Smith CA. Equivalence of Paper-and-pencil and Computerized Self-report Surveys in Older Adults. Comput Hum Behav. 2016;54(C):407-413. doi:10.1016/j.chb.2015.08.033

34. Hall AK, Bernhardt JM, Dodd V, Vollrath MW. The digital health divide: evaluating online health information access and use among older adults. Health Educ Behav. 2015;42(2):202-209. doi:10.1177/1090198114547815

35. Remillard ML, Mazor KM, Cutrona SL, Gurwitz JH, Tjia J. Systematic review of the use of online questionnaires of older adults. J Am Geriatr Soc. 2014;62(4):696-705. doi:10.1111/jgs. 12747 
36. Tian Q. Intergeneration social support affects the subjective well-being of the elderly: Mediator roles of self-esteem and loneliness. J Health Psychol. 2016;21(6):1137-1144. doi:10.1177/1359105314547245

37. Zillmann D, Schmitz A, Skopek J, Blossfeld H-P. Survey topic and unit nonresponse. Quality \& Quantity. 2014;48:2069-2088. doi:10.1007/s11135-0139880-y

38. Zheng R, Spears J, Luptak M, Wilby F. Understanding Older Adults' Perceptions of Internet Use: An Exploratory Factor Analysis. Educational Gerontology. 2015;41(7):504-518. doi:10.1080/03601277.2014.1003495 
All questions have yes/no options

The following questions regard your experiences with movement, use and sleep in the past 4 weeks.

1. Do you have limited movement of your hip?

2. Do you have limited movement of your knee?

3. Do you have limited movement of your ankle?

4. Do you have limited movement of your foot?

5. Do you have limited movement of your toes?

6. Does your leg or foot feel weak?

The following questions relate to symptoms you might experience in your

foot, leg, hip, groin or your lower body in the past 4 weeks.

7. Have you experienced tenderness?

8. Have you experienced swelling?

9. Have you experiences swelling with pitting? (Pitting is when you press firmly on your skin and the dent stays long enough to feel it when you slide the pad of your finger across it.)

10. Have you experienced redness?

11. Have you experienced blistering?

12. Have you experienced firmness/tightness?

13. Have you experienced increased temperature in your leg?

14. Have you experienced heaviness?

15. Have you experienced numbness?

16. Have you experienced stiffness?

17. Have you experienced aching?

18. Have you experienced hip swelling?

19. Have you experienced groin swelling?

20. Have you experienced pockets of fluid?

* Adapted from the Gynaecologic Cancer Lymphedema Questionnaire (GCLQ;

Carter et al., 2010). 
Table 2: Descriptive statistics for MGSIS-5 by age group

\begin{tabular}{|c|c|c|c|c|c|c|c|c|c|c|c|c|}
\hline & \multicolumn{3}{|c|}{$40-49$} & \multicolumn{3}{|c|}{$50-59$} & \multicolumn{3}{|c|}{$60-69$} & \multicolumn{3}{|c|}{ All } \\
\hline $\begin{array}{l}\text { I feel } \\
\text { positively } \\
\text { about my } \\
\text { genitals }\end{array}$ & $\mathrm{N}$ & Mean & SD & $\mathrm{N}$ & Mean & SD & $\mathrm{N}$ & Mean & SD & $N$ & Mean & SD \\
\hline $\begin{array}{l}\text { I am } \\
\text { satisfied } \\
\text { with the } \\
\text { appearance } \\
\text { of my } \\
\text { genitals }\end{array}$ & 14 & 3.36 & 0.84 & 2 & 3.50 & 0.71 & 14 & 3.29 & 0.61 & 30 & 3.33 & 0.71 \\
\hline $\begin{array}{l}\text { I would feel } \\
\text { comfortable } \\
\text { letting a } \\
\text { sexual } \\
\text { partner look } \\
\text { at my } \\
\text { genitals }\end{array}$ & 14 & 3.07 & 0.83 & 2 & 3.50 & 0.71 & 14 & 3.07 & 0.62 & 30 & 3.10 & 0.71 \\
\hline $\begin{array}{l}\text { I think my } \\
\text { genitals } \\
\text { work the } \\
\text { way they are } \\
\text { supposed to } \\
\text { work }\end{array}$ & 14 & 3.43 & 0.85 & 2 & 3.50 & 0.71 & 14 & 3.43 & 0.51 & 30 & 3.43 & 0.68 \\
\hline $\begin{array}{l}\text { I am not } \\
\text { embarrassed }\end{array}$ & 14 & 3.36 & 0.63 & 2 & 4.00 & 0.00 & 14 & 3.07 & 0.92 & 30 & 3.27 & 0.78 \\
\hline
\end{tabular}




\begin{tabular}{|c|c|c|c|c|c|c|c|c|c|c|c|c|}
\hline $\begin{array}{l}\text { about my } \\
\text { genitals }\end{array}$ & & & & & & & & & & & & \\
\hline $\begin{array}{l}\text { I feel } \\
\text { positively } \\
\text { about my } \\
\text { genitals }\end{array}$ & 14 & 3.14 & 1.10 & 2 & 4.00 & 0.00 & 14 & 3.21 & 0.70 & 30 & 3.23 & 0.90 \\
\hline Total score & 14 & 16.36 & 3.75 & 2 & 18.50 & 2.12 & 14 & 16.07 & 2.53 & 30 & 16.37 & 3.11 \\
\hline
\end{tabular}


Table 3: Component matrix for the MGSIS-5

\begin{tabular}{r|rc} 
I feel positively about my & Component & 0.72 \\
genitals & 0.85 & 0.86 \\
I am satisfied with the & 0.93 & 0.68 \\
appearance of my genitals & & \\
I would feel comfortable letting & 0.82 & 0.54 \\
a sexual partner look at my genitals & & \\
I think my genitals work the & 0.74 & 0.62 \\
way they are supposed to work & & \\
I am not embarrassed about & 0.80 & \\
my genitals & &
\end{tabular}




\begin{tabular}{|c|c|c|c|c|c|c|c|c|c|}
\hline Age & 40 & 49 & & 50 & & & All & & \\
\hline & $N$ & $\begin{array}{l}\text { Yes } \\
(\%)\end{array}$ & No $(\%)$ & $N$ & $\begin{array}{l}\text { Yes } \\
(\%)\end{array}$ & No (\%) & $N$ & Yes (\%) & No (\%) \\
\hline Do you have limited movement of your hip? & 14 & $2(14.3)$ & $12(85.7)$ & 14 & $1(7.1)$ & 13(92.9) & 30 & $3(10)$ & $27(90)$ \\
\hline Do you have limited movement of your knee? & 14 & $2(14.3)$ & $12(85.7)$ & 14 & $3(21.4)$ & 11(78.6) & 30 & $5(16.7)$ & $25(83.3)$ \\
\hline Do you have limited movement of your ankle? & 14 & $1(7.1)$ & 13(92.9) & 14 & $1(7.1)$ & 13(92.9) & 30 & $2(6.7)$ & $28(93.3)$ \\
\hline Do you have limited movement of your foot? & 14 & $1(7.1)$ & 13(92.9) & 14 & $1(7.1)$ & 13(92.9) & 30 & $2(6.7)$ & $28(93.3)$ \\
\hline Do you have limited movement of your toes? & 14 & $0(0)$ & $14(100)$ & 14 & $2(14.3)$ & $12(85.7)$ & 30 & $2(6.7)$ & $28(93.3)$ \\
\hline Does your leg or foot feel weak? & 14 & $1(7.1)$ & 13(92.9) & 14 & $2(14.3)$ & $12(85.7)$ & 30 & $3(10)$ & $27(90)$ \\
\hline Have you experienced tenderness? & 14 & $1(7.1)$ & 13(92.9) & 14 & $3(21.4)$ & 11(78.6) & 30 & $4(13.3)$ & $26(86.7)$ \\
\hline Have you experienced swelling? & 14 & $1(7.1)$ & 13(92.9) & 14 & $1(7.1)$ & 13(92.9) & 30 & $2(6.7)$ & $28(93.3)$ \\
\hline Have you experienced swelling with pitting? & 14 & $1(7.1)$ & 13(92.9) & 14 & $0(0)$ & $14(100)$ & 30 & $1(3.3)$ & $29(96.7)$ \\
\hline Have you experienced redness? & 14 & $1(7.1)$ & 13(92.9) & 14 & $1(7.1)$ & 13(92.9) & 30 & $2(6.7)$ & $28(93.3)$ \\
\hline Have you experienced blistering? & 14 & $0(0)$ & $14(100)$ & 14 & $1(7.1)$ & 13(92.9) & 30 & $1(3.3)$ & $29(96.7)$ \\
\hline Have you experienced firmness/tightness? & 14 & $1(7.1)$ & 13(92.9) & 14 & $1(7.1)$ & 13(92.9) & 30 & $2(6.7)$ & $28(93.3)$ \\
\hline $\begin{array}{l}\text { Have you experienced increased temperature in your } \\
\text { leg? }\end{array}$ & 14 & $1(7.1)$ & 13(92.9) & 14 & $2(14.3)$ & $12(85.7)$ & 30 & $3(10)$ & $27(90)$ \\
\hline Have you experienced heaviness? & 14 & $1(7.1)$ & 13(92.9) & 14 & $2(14.3)$ & $12(85.7)$ & 30 & $3(10)$ & $27(90)$ \\
\hline Have you experienced numbness? & 14 & $1(7.1)$ & 13(92.9) & 14 & $4(28.6)$ & $10(71.4)$ & 30 & $5(16.7)$ & $25(83.3)$ \\
\hline Have you experienced stiffness? & 14 & $2(14.3)$ & $12(85.7)$ & 14 & $4(28.6)$ & $10(71.4)$ & 30 & $6(20)$ & $24(80)$ \\
\hline Have you experienced aching? & 14 & $2(14.3)$ & $12(85.7)$ & 14 & $9(64.3)$ & $5(35.7)$ & 30 & $11(36.7)$ & $19(63.3)$ \\
\hline Have you experienced hip swelling? & 14 & $0(0)$ & $14(100)$ & 14 & $0(0)$ & $14(100)$ & 30 & $0(0)$ & $30(100)$ \\
\hline Have you experienced groin swelling? & 14 & $0(0)$ & $14(100)$ & 14 & $0(0)$ & $14(100)$ & 30 & $0(0)$ & $30(30)$ \\
\hline Have you experienced pockets of fluid? & 14 & $1(7.1)$ & 13(92.9) & 14 & $1(7.1)$ & 13(92.9) & 30 & $2(6.7)$ & $28(93.3)$ \\
\hline & $N$ & Mean & $S D$ & $N$ & Mean & $S D$ & $N$ & Mean & $S D$ \\
\hline
\end{tabular}


Total Score

$\begin{array}{lllll}14 & 1.43 & 3.99 & 14 & 2.79\end{array}$

3.21

* Adapted from the Gynaecologic Cancer Lymphedema Questionnaire (GCLQ; Carter et al., 2010). 
Table 5: Rotated component matrix with Varimax rotation for the G3L-20

\begin{tabular}{|c|c|c|c|c|}
\hline & 1 & 2 & 3 & Comm \\
\hline Do you have limited movement of your hip? & 0.10 & 0.05 & 0.59 & 0.37 \\
\hline Do you have limited movement of your knee? & 0.64 & 0.57 & 0.15 & 0.77 \\
\hline Do you have limited movement of your ankle? & 0.81 & $\begin{array}{l}- \\
0.01\end{array}$ & 0.51 & 0.91 \\
\hline Do you have limited movement of your foot? & 0.81 & $\begin{array}{l}- \\
0.01\end{array}$ & 0.51 & 0.91 \\
\hline Do you have limited movement of your toes? & 0.71 & $\begin{array}{l}- \\
0.12\end{array}$ & -0.20 & 0.56 \\
\hline Does your leg or foot feel weak? & 0.82 & 0.03 & 0.32 & 0.77 \\
\hline Have you experienced tenderness? & 0.04 & 0.55 & 0.50 & 0.55 \\
\hline Have you experienced swelling? & 0.15 & 0.69 & 0.68 & 0.97 \\
\hline Have you experienced swelling with pitting? & 0.30 & 0.04 & 0.93 & 0.95 \\
\hline Have you experienced redness? & 0.15 & 0.69 & 0.68 & 0.97 \\
\hline Have you experienced blistering? & $\begin{array}{l}- \\
0.09\end{array}$ & 0.92 & 0.02 & 0.85 \\
\hline Have you experienced firmness/tightness? & 0.15 & 0.69 & 0.68 & 0.97 \\
\hline $\begin{array}{l}\text { Have you experienced increased temperature in } \\
\text { your leg? }\end{array}$ & - & 0.77 & -0.16 & 0.62 \\
\hline Have you experienced heaviness? & 0.76 & $\begin{array}{l}- \\
0.01\end{array}$ & 0.38 & 0.71 \\
\hline Have you experienced numbness? & 0.56 & 0.51 & 0.28 & 0.65 \\
\hline Have you experienced stiffness? & 0.58 & 0.44 & 0.18 & 0.57 \\
\hline Have you experienced aching? & 0.58 & 0.50 & 0.01 & 0.58 \\
\hline Have you experienced pockets of fluid? & 0.33 & 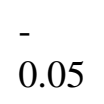 & -0.63 & 0.51 \\
\hline
\end{tabular}

